\title{
Subjective Sleep Quality After a Near-Death Experience
}

\author{
Nicole Lindsay, $\mathrm{PhD}$, and Natasha Tassell-Matamua, $\mathrm{PhD}$ \\ Massey University
}

\begin{abstract}
Findings from several studies suggest near-death experiences (NDEs) may influence sleep quality. In this study, we examined self-reported duration, latency, and quality of sleep in those who had experienced a lifethreatening event and who had and had not reported an associated NDE. Participants were 154 members of the general New Zealand population who completed an online quantitative questionnaire that included the Pittsburgh Sleep Quality Index, Near-Death Experience Scale, Impact of Event Scale-Revised, and Life Changes Inventory-Revised. Both the NDE and non-NDE groups indicated sleep habits had changed after their close encounter with death. Participants slept less, took longer to fall asleep, and experienced more sleep disturbances. However, we found no differences between the groups, suggesting sleep alterations occurred in response to the near-death event rather than specifically to the NDE.
\end{abstract}

KEYWORDS: near-death experiences, sleep quality, PSQI, NDE aftereffects, sleep duration

Near-death experiences (NDEs) are typically vivid and realistic subjective experiences reported by about $10-20 \%$ of people who come close to death. Common features of NDEs include feelings of peace and joy, an impression of being out of the physical body, the perception of bright light, encountering nonmaterial beings, and altered perceptions of time (Zingrone \& Alvarado, 2009). Although there is little consensus as to the cause of NDEs, extensive research over the past 40 years has revealed a consistent pattern of pronounced and pervasive aftereffects following these occurrences (Noyes et al., 2009). Near-death experiencers (NDErs) often claim to have been profoundly changed by their

\footnotetext{
Nicole Lindsay, $\mathrm{PhD}$, is a research officer, and Natasha Tassell-Matamua, $\mathrm{PhD}$, is a senior lecturer, both in the School of Psychology, Massey University, Palmerston North, New Zealand. Correspondence regarding this article should be sent to Dr. Lindsay at email: n.lindsay1@massey.ac.nz.
} 
experience, and psychometric tools designed to measure an array of psychosocial aftereffects, both in the immediate aftermath of the experience and over the long-term, have provided empirical support for such claims (Groth-Marnat \& Summers, 1998; Klemenc-Ketis, 2013; Schwaninger et al., 2002; van Lommel et al., 2001). Personality and value changes include an increased appreciation for life, greater selfacceptance, heightened spirituality, decreased concern for material gain and social status, decreased fear of death, and increased interest in the wellbeing of others. Results of studies comparing those who had NDEs with those who experienced a life-threatening event but did not have NDEs strongly suggest that the NDE, rather than simply the event of coming close to death, is the catalyst for change (KlemencKetis, 2013; Schwaninger et al., 2002; van Lommel et al., 2001).

In addition to well documented psychological changes, a variety of physiological alterations have also been reported post-NDE, including increased allergies, skin sensitivities, changes in body temperature, heightened senses, hyper-sensitivity to light, extra-sensory perception, and altered sleep patterns. Electromagnetic (EM) aftereffects of NDEs have been the subject of recent attention in the literature, with several researchers finding NDErs, compared to survivors of a close brush with death without an NDE, reporting increased EM reactivity, such as sensitivity to electromagnetic phenomena, and activity, such as malfunction of electrical devices in NDErs' vicinities (Fracasso \& Friedman, 2012; Greyson et al., 2015; Nouri \& Holden, 2008; Ring \& Rosing, 1990). Outside of these studies, however, little to no research has been conducted on other putative physiological changes, despite their potential for objective verification.

One area that lends itself well to empirical investigation is the study of NDErs' reported sleep patterns. Anecdotal accounts of changed sleep habits, particularly the need for less sleep, are relatively plentiful in both NDE and popular literature. P. M. H. Atwater (2009), NDE investigator and author of numerous popular NDE works, claimed that altered sleep cycles following NDEs are common. Based on her informal interview sessions with 3,000 adult and 277 child experiencers, Atwater stated that 50-79\% of her NDEr interviewees verified this aftereffect, describing changes such as reduced need for sleep, more vivid dreams, and early morning wakefulness between 3:00-4:00 a.m. (Atwater, 2009).

In the only empirical study comprehensively examining psychophysical changes in the aftermath of an NDE, Ring and Rosing (1990) surveyed 74 NDErs and 54 control participants who were interested 
in NDEs yet had not experienced one themselves. NDErs self-reported far more psychophysical changes $(p<.0001)$, including a decreased need for sleep: $39.2 \%$ of NDErs vs. $16.7 \%$ of controls. Although the authors were at a loss to explain these differences, they tentatively speculated that "the psychophysical changes reported in connection with NDEs reflect some sort of psychobiological transformation" (p. 233). However, Ring and Rosing also acknowledged an equally reasonable explanation was that any changes may be directly traceable to differences in lifestyle, with NDErs possibly having changed such things as diet, exercise, and meditative practice following their NDEs.

It is also plausible that a certain neurobiological predisposition may increase the likelihood of having an NDE and may also be responsible for the other physical anomalies that NDErs report. Several authors have suggested the possibility that NDErs are physiologically distinct from others even prior to the near-death event (e.g., Britton \& Bootzin, 2004; Nelson et al., 2006: Nelson et al., 2007). Britton and Bootzin (2004) investigated temporal lobe functioning in NDErs and controlsthose who had never been close to death-and discovered the former had more temporal lobe epileptiform electroencephalographic activity as well as significantly more temporal lobe epileptic symptoms. Because sleep is related to epileptiform activity (Malow, 1996), the researchers conducted an overnight polysomnographic (PSG) sleep study, finding the NDErs $(n=23)$ had different sleep patterns. The NDE group slept about an hour less than the age- and gender-matched control group, and the onset of rapid eye movement (REM) sleep was delayed. The NDE group also had fewer REM sleep periods; however, the researchers found no between-groups difference in the amount of overall REM sleep. The authors concluded that altered temporal lobe functioning may be involved in NDEs and that NDErs may be physiologically predisposed to the experience. However, as the study did not include participants who also came close to death with no NDE, it is uncertain whether differences were the result of generalized trauma to the brain rather than to NDEs per se. It is equally possible that increased epileptiform electroencephalographic activity occurs as a consequence of NDEs.

A connection between NDEs and altered REM functioning has also been proposed by Nelson, Mattingly, Lee, and Schmitt (2006). Nelson et al. (2006) claimed certain persons may have arousal systems predisposed to REM intrusion, and this dynamic may underlie some of the subjective experiences of NDEs. REM sleep is a normal phase of sleep; however, it can also occur while an individual is awake-a 
phenomenon known as REM intrusion. REM intrusion usually occurs upon falling asleep or waking up and manifests as visual and auditory hallucinations and sleep paralysis. Nelson et al. (2006) found NDErs $(n=55)$ self-reported more episodes of REM intrusion at some time in their lives, compared to age- and gender-matched controls from among available medical personnel and personal contacts. Based on their findings, the researchers suggested that REM intrusion may therefore be responsible for many elements of NDEs. This hypothesis is relatively controversial, however. As Long and Holden (2007) noted, the often bizarre and fragmented subjective experience of REM intrusion bears only a slight resemblance to the lucid, structured experience of NDEs. In a similar manner to Britton and Bootzin (2004), Nelson et al. (2006) also presumed that REM intrusion is a predisposing factor, yet the likelihood of experiencing REM intrusion may increase postNDE rather than exist pre-NDE. Nevertheless, even if REM intrusion does not adequately explain the subjective experience of NDE, it may possibly be related to the sleep abnormalities observed in NDErs. For example, if the individual experiences more REM intrusion during periods of wakefulness, perhaps this is why NDErs require fewer REM episodes during actual sleep, as objectively measured by Britton and Bootzin (2004).

Such findings lend support to the anecdotal claims of altered sleep patterns following NDEs. Possible neurobiological bases for this anomaly, as speculative as they are, can also be extrapolated from the literature. In the first instance, however, it is useful to understand more fully NDErs' sleep patterns from a subjective standpoint. Current knowledge is limited, hampered by over-reliance upon non-empirical data, relatively small sample sizes, and a lack of adequate control groups. Nelson et al. (2006) and Britton and Bootzin (2004), for example, did not include participants who had come close to death without an NDE, making it difficult to determine whether any observed changes related to the NDE specifically. It may be the event of coming close to death that results in altered sleep patterns, regardless of whether an NDE occurred or not. Other questions remain. If sleep duration is reduced in NDErs, is the objective quality of sleep enhanced? Or, are they receiving the same amount of sleep as prior to their NDE, but the subjective quality of the sleep is enhanced? Or, is the presumed shortened duration of sleep related to some other factors, such as other reported psychologically beneficial aftereffects of NDEs? Relatedly, sleep research tends to indicate that longer REM latency is related to a greater drive for sleep. That is, if sleep need is high due to 
behavioral or physiological sleep restriction, then slow wave sleep predominates in the first portion of the night, meaning that REM sleep occurs later in the sleep cycle. However, given that many NDErs have reported a reduced drive/need for sleep, the previous findings of delayed REM sleep seem somewhat paradoxical.

The purpose of the following study was to create a foundation for examining the relationship between NDEs and subsequent sleep. Specifically, using a quantitative questionnaire design based on a wellestablished sleep index, we investigated self-reported subjective duration, latency, and quality of sleep in those who have had a close brush with death with or without an associated NDE. We attempted to answer several of the questions posed above, the primary ones being whether NDEs result in altered sleep habits and whether those who experience NDEs differ from those who have also come close to death without NDE. Conversely, might any sleep changes be related instead to medical conditions arising from the near-death event-or to other factors such as stress, depression, trauma, or other physiological impairment. In other words, is it the NDE or the survival of a life-threatening event that is instrumental to change? If differences are found, are there any features of the NDE that might reliably predict altered sleep patterns, and/or are they associated with other NDE aftereffects? The preceding questions were formulated prior to commencement of the study. Over the course of analysis other questions emerged, such as whether the sleep habits of the current sample differ from the general population; thus, we added this additional analysis post-hoc.

\section{Method}

\section{Participants}

Recruitment strategies included print and online media, such as newspapers, and a snowballing technique using acquaintanceship networks. All participants self-selected into the study, and data collection occurred over a four-month period between December 2016 and April 2017.

The sample of 154 participants comprised both male and female members of the general New Zealand population, aged 18 years and older, who self-identified as having had a close brush with death at some stage in their life. One hundred and thirteen persons (73\%) met the NDE inclusion criteria, determined by a score of 7 or more points on the NDE Scale (see below). These participants comprised the NDE 
Table 1 Demographics of NDE and Non-NDE Participants

\begin{tabular}{|c|c|c|c|c|c|}
\hline Variable & $\begin{array}{l}\text { NDErs } \\
(n=113)\end{array}$ & $\begin{array}{l}\text { Non-NDErs } \\
(n=41)\end{array}$ & Statistic & $p$ & $\begin{array}{c}\text { Effect } \\
\text { size }\end{array}$ \\
\hline $\begin{array}{c}\text { Gender } \\
\text { Female } \\
\text { Male }\end{array}$ & $\begin{array}{l}60.7 \% \\
39.3 \%\end{array}$ & $\begin{array}{l}36.6 \% \\
63.4 \%\end{array}$ & $\mathrm{X}^{2}(\mathrm{df}=1)=7.04$ & .008 & $V=.22$ \\
\hline Age & $46-55$ yrs & $46-55$ yrs & $\mathrm{H}(\mathrm{df}=1)=.94$ & .33 & NA \\
\hline Education & & & $\mathrm{H}(\mathrm{df}=1)=.14$ & .70 & NA \\
\hline High School & $30.1 \%$ & $34.1 \%$ & & & \\
\hline Undergraduate & $29.2 \%$ & $17.1 \%$ & & & \\
\hline Post graduate & $25.7 \%$ & $29.3 \%$ & & & \\
\hline Other & $15.0 \%$ & $19.5 \%$ & & & \\
\hline Ethnicity & & & $\mathrm{H}(\mathrm{df}=1)=1.76$ & .18 & NA \\
\hline Māori & $7.1 \%$ & $2.4 \%$ & & & \\
\hline NZ Pākehā & $51.3 \%$ & $73.2 \%$ & & & \\
\hline European & $22.1 \%$ & $9.8 \%$ & & & \\
\hline American & $7.1 \%$ & $9.8 \%$ & & & \\
\hline Other & $12.4 \%$ & $4.9 \%$ & & & \\
\hline Marital status & & & $\mathrm{H}(\mathrm{df}=1)=.53$ & .47 & NA \\
\hline Single & $20.4 \%$ & $36.6 \%$ & & & \\
\hline Married/defacto & $61.1 \%$ & $61.0 \%$ & & & \\
\hline Widowed & $4.4 \%$ & $2.4 \%$ & & & \\
\hline $\begin{array}{l}\text { Year of near-death } \\
\text { event }\end{array}$ & 1999 & 2000 & $\mathrm{H}(\mathrm{df}=1)=.14$ & .33 & NA \\
\hline $\begin{array}{l}\text { Presence of medical } \\
\text { condition }\end{array}$ & $59.3 \%$ & $68.3 \%$ & $\mathrm{X}^{2}(\mathrm{df}=1)=.94$ & .31 & NA \\
\hline
\end{tabular}

group. Forty-one persons (27\%) reported an experience near death that scored below 7 points on the NDE Scale. These participants were allocated to the non-NDE group.

Descriptive statistics were used to summarize the demographic characteristics of the sample (see Table 1). See Data Analysis section below for explanation of analysis. No significant differences were found between the groups on any of the seven variables except gender, with a small effect. Significantly more females comprised the NDE group than the non-NDE group. 


\section{Procedure}

The online questionnaire was implemented by the Massey University School of Psychology data analyst, using the Qualtrics online software, and was accessible via a webpage developed specifically for the research. The questionnaire was comprised of a series of established measures assessing the presence of NDE, several components of sleep quality, general life changes, and symptoms associated with trauma, described further below. Seven questions captured demographic information.

\section{Measures}

To assess whether an NDE occurred during the near-death event, the survey included the NDE Scale (Greyson, 1983). The NDE Scale is a widely used measure in the field of near-death studies that assigns a weighted score to 16 commonly reported features of NDEs, determined through pilot studies with persons who had come close to death. Examples items include "Did you see, or feel surrounded by, a brilliant light?" and "Did you have a feeling of peace or pleasantness?" Scores can vary from $0-32$, and a score of 7 or more is classed as an NDE (Greyson, 1983), with higher scores representing "deeper" or more intense experiences. Scores below the cut-off point of 7 are not considered indicative of NDEs. The NDE Scale has demonstrated high internal consistency (Cronbach's alpha $=.87$ ), good split-half reliability $(r=.84, p<.001)$, and test-retest reliability over both a short-term period of six months $(r=.92, p<.001)$ and the long term $(r=.83, p<$ .001 ; Greyson, 1983, 2007).

Sleep quality was assessed using the Pittsburgh Sleep Quality Index (PSQI; Buysse et al., 1989), an 18-item questionnaire measuring subjective quality and patterns of sleep in adults over the last month. Seven components are assessed: subjective sleep quality, sleep latency - how long it takes to fall asleep, sleep duration, habitual sleep efficiency - how long a person is asleep in comparison to their time in bed, sleep disturbances, sleep medication use, and daytime dysfunction - such as whether the person feels tired the next day. Four questions require a numerical response, for example, "What time have you usually gone to bed?" and 14 questions require a Likert type response, for example, "During the past month, how much of a problem has it been for you to keep up enough enthusiasm to get things done?" Seven component scores are calculated, each ranging from 0 to 3 , and 
a global PSQI score is calculated by summing the components scores. Thus, total scores can range from 0 to 21 , with lower scores indicating better sleep quality and a score of 5 or greater indicative of poor sleep quality. Mollayeva et al. (2016) reviewed 37 studies that assessed the psychometric properties of the PSQI, including construct validity, known-group validity, internal consistency, and test-retest reliability. Results ranged from poor to excellent, with the majority designated fair. In this study, participants also responded to five additional questions designed to assess sleep quality before the near-death event, such as "Do you think your current sleep habits over the past month are different to your sleep habits BEFORE your near-death incident?"

We also used the Impact of Events Scale-Revised (IES-R; Weiss \& Marmar, 1997) to determine whether any changed sleep patterns were related to the difficulties people sometimes have after stressful life events, such as a near-death incident. The IES-R has a threefactor structure that delineates three clusters of symptoms; intrusion - repeated thoughts about the trauma, avoidance-effortful avoidance of situations that serve as reminders of the trauma, and hyperarousal-physiological hyperarousal. Each question begins with the stem, "How much have you been distressed or bothered by these difficulties?" and responses are selected from a 5-point Likert scale ranging from " $0=$ Not at all" to " $4=$ Extremely." The 22 -item scale includes three items related to sleep: "I had trouble falling asleep," "I had trouble staying asleep," and "I had dreams about it." Item responses are compiled into a total score. Higher scores indicate a greater level of distress or difficulty, with a total score of 24-32 indicating that PTSD is a clinical concern and 33 indicating a probable diagnosis of PTSD. Sundin and Horowitz (2002) reviewed 66 studies that analyzed the IES's reliability and validity, finding it was a psychometrically sound, useful measure of negative stress reactions after a range of traumatic events.

To determine whether any altered sleep patterns were related to other commonly reported aftereffects of NDEs, we included the Life Changes Inventory-Revised (LCI-R; Greyson \& Ring, 2004). The LCI-R is a 50-item measure designed to assess the degree of life change after an NDE. It is composed of nine personal value domains that include appreciation for life, self-acceptance, concern for others, concern for worldly achievement-competitive tendencies, concern for material things, concern with social/planetary values, quest for meaning/sense of purpose, spirituality, religiousness, and appreciation of death-fear of death, and interest in death and dying. Example items include: 
"Since my NDE, my appreciation for the ordinary things of life has ..." and "Since my NDE, my desire to help others has ...". Participants select their response from a Likert scoring key ranging from +2 for strongly increased, to 0 for no change, to -2 for strongly decreased. Extent of overall change across all value domains is indicated by calculating the mean of all 50 responses. A mean score for each domain can be also be calculated. Recent studies using the LCI-R have indicated adequate psychometric properties (Goza et al., 2014; TassellMatamua et al., 2017).

\section{Data Analysis}

Data analyses were performed using SPSS 25.0 for Windows. Descriptive statistics were used to summarize the demographic characteristics of the sample. Chi squared tests and Kruskal-Wallis ANOVAs were performed to assess differences between groups on seven demographics variables. To test for differences against a hypothesized meangeneral population scores-we used one-sample $t$ tests. ShapiroWilk tests revealed violations of the normality assumption on nearly all measures, so Mann-Whitney $U$ tests and Kruskal-Wallis ANOVAs were performed to assess differences between NDE and non-NDE groups. Spearman's Rho tests were also used to assess for any correlations between measures.

A significance level was set at $p<.05$ for all analyses. To interpret effect sizes, we used Cohen's (1988) cautious guidelines: for Mann Whitney $U r, .1$ for a small, .3 for a medium, and .5 for a large effect; and for Kruskal-Wallis ANOVA $f$, .01 for a small, .25 for a medium, and .40 for a large effect. To interpret effect sizes in chi-squared tests, we used Cramer's $V$ : With 1 degree of freedom (df), a value of .1 indicated a small, .3 a medium, and .5 a large effect.

\section{Results}

\section{NDE Scale Scores}

Out of a possible total score range from 0 to 32, NDE Scale total scores for all 154 participants ranged from 0 to 30, with a mean score of $10.96(S D=6.86)$. The scale showed good internal consistency (Cronbach's $\alpha=.86$ ). Participants whose scores met the criterion of 7 or higher had total scores ranging from 7 to 30 with a mean score of $13.79(S D=5.70)$. 


\section{Sleep Quality}

To determine whether the current sample's sleep habits could be considered 'normal' or not, and whether any differences between NDErs and non-NDErs were evident, scores on the PSQI were assessed. For all 154 participants, out of a possible global score range of 0-21, PSQI global scores ranged from $1-21(M=10.15, S D=4.40)$. The global PSQI mean of the NDEr group was slightly less $(M=10.11, S D=1.77)$ than the non-NDEr group $(M=10.24, S D=1.74)$. Of the total sample, $132(85.7 \%)$ scored 5 or higher, indicating the presence of sleep abnormalities. Difficulties were reported by 95 (85.2\%) of the NDEr group and 34 (81.1\%) of the non-NDEr group. Mann Whitney $U$ tests revealed no significant differences between the NDE and non-NDE group for PSQI global scores or any of its components.

Although scores were comparable for both groups, we noticed that PSQI scores overall were relatively high-with a substantial majority of participants scoring 5 or greater. To assess whether the present sample differed from normal sleepers in the New Zealand population, one-sample $t$ tests-which are considered 'robust' against violations of normality-were conducted. Compared to the general New Zealand population mean PSQI global score of 3.9, our participants scored significantly higher: total sample, $t(124)=15.90, p<$ .001 ; NDErs, $t(87)=13.68, p<.001$; non-NDErs, $t(36)=8.10, p<.001$. Sleep duration was also significantly less: total sample, $t(136)=-6.47$, $p<.001$; NDErs, $t(94)=-6.30, p<.001$; non-NDErs, $t(40)=-2.75$, $p=.009$; sleep latency significantly longer: total sample, $t(125)=0.47$, $p<.001$; NDErs, $t(100)=9.44, p<.001$; non-NDErs, $t(38)=4.69, p<$ .001 ; and number of awakenings significantly higher: total sample, $t(138)=11.21, p<.001$; NDErs, $t(98)=9.82, p<.001$; non-NDErs, $t(38)=5.42, p<.001$. Mean scores for the overall sample and each group are summarized in Table 2.

For the total sample, PSQI global scores were negatively correlated with age $(r=-.23, p=.012)$ and positively correlated with year of near-death incident $(r=.26, p=.003)$; thus, sleep quality tended to be worse for our participants who were younger and whose incident had occurred more recently. For NDErs, PSQI Scores were significantly associated with year of the near-death incident $(r=.32, p=.002)$; however, this relationship was not evident in the non-NDEr group. Conversely, for non-NDErs there was a significant negative correlation between age and PSQI scores $(r=-.49, p=.002)$, but not for NDErs. Because of the significantly greater number of women in the NDEr participant group, gender might have represented a confound- 
Table 2 Self-Reported Sleep Variables on the Pittsburgh Sleep Quality Index (PSQI)

\begin{tabular}{|c|c|c|c|c|c|c|c|c|}
\hline & \multicolumn{2}{|c|}{$\begin{array}{l}\text { General NZ } \\
\text { population }^{1} \\
(n=57)\end{array}$} & \multicolumn{2}{|c|}{$\begin{array}{l}\text { Total Sample } \\
\quad(N=154)\end{array}$} & \multicolumn{2}{|c|}{$\begin{array}{l}\text { NDE group } \\
\quad(n=112)\end{array}$} & \multicolumn{2}{|c|}{$\begin{array}{l}\text { Non-NDE group } \\
(n=42)\end{array}$} \\
\hline & Mean & $95 \% \mathrm{CI}^{2}$ & Mean & $95 \%$ CI & Mean & 95\% CI & Mean & 95\% CI \\
\hline PSQI total ${ }^{3}$ & 3.90 & $\begin{array}{r}(3.4 \\
4.4)\end{array}$ & 10.15 & $\begin{array}{l}(9.37 \\
10.93)\end{array}$ & 10.11 & $\begin{array}{l}(9.21 \\
11.01)\end{array}$ & 10.24 & $\begin{array}{l}(8.66, \\
11.83)\end{array}$ \\
\hline $\begin{array}{l}\text { Time in bed } \\
\text { (hours) }\end{array}$ & 8.35 & $\begin{array}{l}(8.15, \\
8.57)\end{array}$ & 8.47 & $\mathrm{n} / \mathrm{a}$ & 7.95 & $\mathrm{n} / \mathrm{a}$ & 8.99 & $\mathrm{n} / \mathrm{a}$ \\
\hline $\begin{array}{l}\text { Sleep Dura- } \\
\text { tion (hours) }\end{array}$ & 7.43 & $\begin{array}{r}(7.23, \\
7.63)\end{array}$ & 6.40 & $\begin{array}{r}(6.11 \\
6.70)\end{array}$ & 6.28 & $\begin{array}{r}(5.92 \\
6.55)\end{array}$ & 6.68 & $\begin{array}{r}(6.13 \\
7.23)\end{array}$ \\
\hline $\begin{array}{l}\text { Sleep } \\
\text { Latency } \\
\text { (minutes) }\end{array}$ & 10.70 & $\begin{array}{r}(8.6, \\
12.7)\end{array}$ & 24.20 & $\begin{array}{r}(19.2, \\
28.5)\end{array}$ & 24.50 & $\begin{array}{r}(23.2, \\
29.7)\end{array}$ & 23.90 & $\begin{array}{r}(18.5, \\
27.2)\end{array}$ \\
\hline $\begin{array}{l}\text { Number of } \\
\text { awakenings }\end{array}$ & 1.20 & $\begin{array}{r}(1.0 \\
1.4)\end{array}$ & 1.90 & $\begin{array}{l}(1.8, \\
2.0)\end{array}$ & 1.90 & $\begin{array}{l}(1.7, \\
2.0)\end{array}$ & 1.80 & $\begin{array}{r}(1.6, \\
2.1)\end{array}$ \\
\hline $\begin{array}{l}\text { Sleep } \\
\text { Efficacy }^{5}\end{array}$ & $89.1 \%$ & $\begin{array}{c}(87.6, \\
90.6)\end{array}$ & $75.6 \%$ & $\mathrm{n} / \mathrm{a}$ & $79.0 \%$ & $\mathrm{n} / \mathrm{a}$ & $74.3 \%$ & $\mathrm{n} / \mathrm{a}$ \\
\hline
\end{tabular}

Notes: ${ }^{1}$ Baskett et al., 2003

${ }^{2} \mathrm{CI}=$ confidence interval; $95 \%$ of the sample fell within the range (x.x, y.y).

${ }^{3} 5$ or greater $=$ poor sleep quality

${ }^{4}$ Sleep latency $=$ how long to fall asleep

${ }^{5}$ Sleep efficiency $=$ time asleep / time in bed (from lights out to get up)

ing variable, but we found no significant correlations between gender and PSQI total scores. No other significant associations between PSQI global scores and other demographic variables, including presence of a medical condition, were observed.

There was no significant correlation between NDE Scale scores and the PSQI for the total sample. However, for the NDE group, Spearman's Rho yielded significant positive correlations between NDE Scale scores and PSQI global scores $(r=.25, p=.02)$, sleep disturbances $(r=.24, p=.02)$, and sleep duration $(r=.23, p=.02)$, indicating the deeper the NDE, the more likely participants reported sleep difficulties. Inspection of items comprising the sleep disturbance component showed "waking up in the middle of the night or early morning" had the highest median score.

\section{Posttraumatic Stress Symptoms}

To determine any relationships between sleep scores and the presence of trauma, we assessed participants on the Impact of Events Scale- 
Table 3 Mean Scores for the Impact of Events Scale-Revised (IES-R) by Group Type

\begin{tabular}{|c|c|c|c|c|c|c|}
\hline \multirow[b]{2}{*}{ Variable } & \multicolumn{2}{|c|}{ Total $(N=151)$} & \multicolumn{2}{|c|}{ NDE group $(n=109)$} & \multicolumn{2}{|c|}{ Non-NDE group $(n=42)$} \\
\hline & Mean & $95 \% \mathrm{CI}^{1}$ & Mean & 95\% CI & Mean & $95 \% \mathrm{CI}$ \\
\hline IES-R t & .53 & $(24.3$ & 28.26 & $(24.56,31.95)$ & 25.60 & $(18.86,32.33)$ \\
\hline Hyperarousal & 6.27 & $(5.30,7.23)$ & 6.22 & $(5.11,7.23)$ & 6.40 & $(4.38,8.43)$ \\
\hline Intrusion & 11.89 & $(10.55,13.22)$ & 12.41 & $(10.86,13.95)$ & 10.57 & $(7.87,13.27)$ \\
\hline Avoidance & 8.78 & $(7.50,10.07)$ & 9.14 & $(7.57,10.71)$ & 7.88 & $(5.63,10.13)$ \\
\hline
\end{tabular}

Notes: ${ }^{1} \mathrm{CI}=$ confidence interval.

${ }^{2} \mathrm{~A}$ score of $24-32$ indicates PTSD is a clinical concern, and 33 and above indicates a probable diagnosis of PTSD.

Revised. In this study, IES-R reliability was excellent (Cronbach's $\alpha=.94$ ). Out of a total possible score range of 0 to 88 , scores for all participants ranged from 0 to 75 , with a mean score of $27.53(S D=18.85)$. The mean score for the NDErs was $28.26(S D=17.78)$ and for the non-NDErs was 25.60 ( $S D=21.61$; see Table 3 for more details). Shapiro Wilks statistics indicated normality assumptions were violated, so we conducted Mann Whitney $U$ tests to determine whether any differences existed between the two groups. The difference between groups was not significant for the IES-R total score $(\mathrm{df}=1, U=0.43)$, nor were any differences found for the subscales. A Spearman's Rho indicated a significant correlation between scores on the IES-R and the PSQI $(r=.41, p<.001)$. No significant correlations were found for the IES-R and the NDE Scale. For the overall sample, the IES was significantly, positively correlated with year of near-death incidence $(r=.35, p<.001)$ and negatively with age $(r=-.17, p=.04)$, indicating the younger the participant and more recent the event, the more trauma symptoms were reported. No other correlations with the IES-R were apparent.

\section{Life Changes}

A further research question was whether other life changes occurring after near-death events correlated to sleep habits. For the Life Changes Index-Revised, Cronbach's alpha indicated our administration had adequate internal reliability $(\alpha=.74)$. Out of a possible total score range of -100 to 100 , scores ranged from -92 to 72 for all participants, with a mean score of $21.27(S D=24.26)$. The mean score for the NDErs was $23.04(S D=26.09)$ and for the non-NDErs was 16.71 
Table 4 Scores on the Life Changes Index-Revised (LCI-R) by Group

\begin{tabular}{lccccc}
\hline \multicolumn{1}{c}{ LCI-R variable } & $\begin{array}{c}\text { NDE group } \\
\text { mean rank } \\
(n=\mathbf{1 1 1})\end{array}$ & $\begin{array}{c}\text { Non-NDE group } \\
\text { mean rank } \\
(n=\mathbf{4 2})\end{array}$ & $U$ & $p$ & $r$ \\
\hline LCI-R total & 66.96 & 51.17 & 1161.00 & .03 & .29 \\
Appreciation for life & 82.77 & 61.76 & 1691.00 & .008 & .23 \\
Self-acceptance & 81.66 & 64.68 & 1813.50 & .03 & .19 \\
Concern for others & 81.54 & 65.79 & 1860.00 & .05 & .19 \\
Worldly achievement & 71.74 & 91.97 & 2926.00 & .02 & .20 \\
Social/planetary concern & 81.11 & 66.13 & 1874.50 & .06 & .16 \\
Life purpose & 84.94 & 56.02 & 1450.00 & .001 & .32 \\
Religiosity & 73.65 & 85.85 & 2702.50 & .12 & .13 \\
Spirituality & 82.76 & 61.79 & 1692.00 & .009 & .23 \\
Appreciation for death & 84.02 & 58.45 & 1552.00 & .001 & .28 \\
\hline
\end{tabular}

$(S D=18.39)$. Shapiro Wilks statistics indicated normality assumptions were violated, so we conducted a series of Mann Whitney $U$ tests to assess group differences on the LCI-R and associated subscales. Results indicated a significant difference with small effect between the groups for total LCI-R scores and for all subscales except social/ planetary concern and religiosity, indicating NDErs were more likely to report significant life changes. See Table 4 for details.

A Spearman's Rho test revealed a significant correlation between NDE Scale scores and the LCI-R $(r=.28, p<.002)$. No correlation was found between the LCI-R total score or subscale scores and either the PSQI or the IES-R total scores.

Finally, based on findings at the bivariate level, we conducted linear regression analyses to determine which variables significantly predicted sleep scores in each group. NDE score, year of near-death incident, current age, and IES scores (previous significant correlations) were included in the model. Presence of a medical condition (dummy coded: $0=$ no, $1=$ yes), was also entered as a covariate, as it may potentially influence sleep habits. For the NDE group, results indicated these variables explained $57.1 \%$ of the variance in global scores, $R^{2}=.32, F(5,87)=7.90, p<.001$. NDE Scale scores contributed significantly to the model (beta $=.274, p=.004$ ), as did IES scores (beta $=.325, p=.002)$ and year of near-death incident (beta $=.235$, $p=.035)$. Neither age nor the presence of a medical condition were significant predictors. 
A similar regression was conducted for the non-NDE group. Results showed these variables explained $68.6 \%$ of the variance in global scores, $R^{2}=.47, F(4,35)=5.33, p<.001$. Age contributed significantly to the model (beta $=-.487, p=.003$ ), as did IES scores (beta $=.462$, $p=.007)$. Neither NDE depth, presence of medical conditions, nor year of the near-death incident were significant predictors.

\section{Discussion}

The results of this study support numerous anecdotal accounts and existing empirical evidence describing altered sleep patterns in NDErs. According to participants' self-assessments, both NDE and non-NDE groups exhibited sleep abnormalities. Both groups reported that their sleep habits had changed after their near-death event, with $69 \%$ of NDErs and $64 \%$ of non-NDErs indicating 'yes' to this question. The Pittsburgh Sleep Quality Index (PSQI) scores for both groups were reasonably high, with mean scores of approximately 10.11 and 10.24 respectively-well above the PSQI threshold of 5 for what is considered healthy sleep.

In lieu of a control group comprised of those who have never come close to death, PSQI scores were compared to average sleep scores for the general New Zealand public. According to Walch et al. (2016), New Zealanders on average go to sleep at 10:48 p.m. and awaken at 6:54 a.m. - an average of 8 hours and 6 minutes sleep. Using the PSQI, Baskett et al. (2001; 2003) found the normal sleepers in their New Zealand study slept a mean time of 7.43 hours and had a sleep latency time of approximately 10 minutes. By contrast, participants in the current study exhibited significant differences. NDErs slept for 6.24 hours and non-NDErs for 6.68 hours-approximately one hour less than the figures reported by Baskett and colleagues. Sleep latency was over twice as long, and NDErs were $59 \%$ more likely to experience sleep disturbances than normal sleepers, with non-NDErs $52 \%$ more likely. Thus, when compared to the general New Zealand population, differences in our sample are clearly apparent.

A significant positive correlation was found between the NDE scale and PSQI global scores, as well as some of the sleep categories. Those who experienced deeper NDErs reported more sleep disturbances, particularly waking up in the middle of the night or early morning, as well as a shorter duration of sleep. Interestingly, the changes reported here reflect the informal observations described by Atwater (2009), who claimed NDErs sleep less than others and often experience early 
morning awakening around 3:00-4:00 a.m. Our data were also consistent with research results of Britton and Bootzin (2003) who found the NDErs in their study slept on average one hour less than the control group. Whether these changes can be considered indicative for all NDErs is unknown; however, it does suggest those who experience more intense NDEs are more likely to experience the specific types of sleep alterations previously outlined in the NDE literature.

What is less clear is the role of the NDE in mediating these changes. Previous studies have not compared NDErs sleep patterns with others who have also come close to death but with no NDE, meaning any changes have been attributed to the NDE itself. In the present study, we found no significant differences between NDErs and non-NDErs for any of the sleep measures, strongly suggesting these abnormalities resulted from the actual near-death event or more generalized trauma to the brain. A significant association between the Impact of Events Scale (IES) and PSQI, and results of the regressions, further suggests that these changes are likely trauma related rather than unique to the NDE. Overall scores on the IES were high for both groups, with a mean score of 28.26 for NDErs and 25.60 for the non-NDErs, and not significantly different. According to Weiss (2007), scores that exceed 24 can be quite meaningful, and a score of 24 or more is considered a clinical concern. Persons with scores this high who do not have full PTSD will have partial PTSD or at least some of the symptoms. Sleep problems are considered a central feature of PTSD, with nightmares, insomnia, sleep apnea, and periodic limb movements highly prevalent in PTSD patients (Spoormaker \& Montgomery, 2008). From an objective standpoint, researchers have recorded highly variable sleep alterations that include shorter sleep duration, increased sleep latency, increased stage 1 sleep, decreased slow wave sleep, and increased REM sleep (Pace-Schott et al., 2015). It is evident our data aligns closely with many of these PTSD-related sleep abnormalities, further suggesting that acute trauma arising from the near-death event, rather than specifically an NDE, primarily relates to any altered sleep patterns.

The high level of posttraumatic symptoms seen in the NDE group is somewhat at odds with existing literature, however, as well as with our own findings using the LCI-R. Using an earlier version of the IES, Greyson (2001) found that although NDErs had relatively high scores $(M=19.6)$, they were not at a level of clinical significance. Britton and Bootzin (2003) found the objective sleep patterns of NDErs were unrelated to negative stress reactions such as PTSD. Furthermore, 
the literature assessing NDE aftereffects has overwhelmingly associated NDEs with positive psychological transformation, with reports of PTSD amongst NDE survivors scarce (Greyson, 2001, Noyes et al., 2009; van Lommel, et al., 2001). Instead, NDErs tend to exhibit high levels of post-traumatic growth and more positive coping strategies than matched controls (Britton \& Bootzin, 2003; Khanna \& Greyson, 2015). Our own findings show NDErs were significantly more likely to report positive life changes relative to non-NDErs which does not suggest, on the surface at least, a high level of distress or dysfunction in the NDErs' everyday lives.

The meaning attached to the near-death event is likely to be important. Although the IES is designed to assess levels of psychological distress after acute trauma, some sequelae may not necessary be viewed negatively by NDErs. Inspection of means for each of the three IES subcategories (intrusion, hyperarousal and avoidance) showed the NDErs were more likely to report symptoms of intrusion, for example, "I thought about it when I didn't mean to" and "I felt as if it didn't happen or wasn't real," than other types of symptoms. Although recurrent, intrusive memories of the event may be distressing for some types of trauma, such as rape or military combat (Shalev et al., 2017), existing NDE literature indicates these recollections are rarely upsetting for NDErs. On the contrary, many become preoccupied with their NDE, enjoy talking about it, and actively strive to relive it (Noyes, et al., 2009). Our findings are similar to those of Greyson (2001) who found NDErs reported twice as many intrusive symptoms of PTSD than avoidance symptoms, suggesting they did not make a great effort to avoid these thoughts. Because NDE survivors tend to view their NDE in positive terms, Greyson (2001) concluded the posttraumatic symptoms reported by NDErs suggests a "nonspecific response characterized by inadequate cognitive processing of a catastrophic event, rather than symptoms of a discrete psychiatric disorder" (p. 372).

In conjunction with others' findings, our results tentatively suggest there may be an underlying neurophysiological basis for altered sleep patterns in those who experience near-death events (or other types of trauma), rather than these issues arising solely from psychological distress. These issues likely occur as a consequence of the near-death event rather than predate it, as (a) most of our participants reported that their sleep changed following their near-death event, and (b) the possibility our entire sample was predisposed to sleep abnormalities seems unlikely. Relatedly, an accumulating literature attests that dis- 
turbed sleep in PTSD patients is a core feature of the disorder rather than a secondary or residual symptom. Sleep abnormalities may arise independently and may actually worsen PTSD or present a risk factor for the subsequent development of PTSD (Pace-Schott et al., 2015). In support of this hypothesis, studies have found that treating the sleep disorder as a primary concern also alleviates overall PTSD symptom severity (Spoormaker \& Montgomery, 2008). Conversely, sleep disturbances often continue as a residential complaint even after successful PTSD treatment (Bisson, et al., 2007). Pace-Schott et al. (2015) hypothesized therefore that sleep disturbance resulting from a traumatic event, or predating the traumatic experience, may contribute to the etiology of PTSD. Our findings further support the idea that sleep issues may arise independently and are not necessarily related to psycho-pathogenic outcomes of trauma.

However, we cannot discount the possibility that many NDErsand non-NDErs - in our sample do have PTSD or partial PTSD, in which case genuine psychological distress accounts for their sleep issues. Although evidence suggests NDErs may process their experience differently, it would be premature to dismiss the NDE group as less traumatized, particularly as scores for both groups were similar. Although other research has not associated NDEs with significant negative stress, this result may potentially relate to differences in sampling strategy. Notably, our participants were drawn from the general population of New Zealand rather than an existing pool of NDErs; therefore, they may be more representative of the wider population of NDErs. In contrast to the work of Britton and Bootzin (2003) and Greyson (2001), our study did not involve recruitment of known NDErs-for example, those who had previously contacted the author or those affiliated with NDE support groups. Such participants are highly self-selected and may have been exposed to existing NDE information, as well as each other, so they may have been more likely to have normalized their experience, received more social support, and integrated the NDE successfully into their lives, thereby protecting themselves from the more distressing PTSD symptoms. PTSD research has shown that people react differently to stressful or traumatic events. Prevalence rates differ depending on gender, social background, type of trauma experienced, social support, and country of residence (Shalev et al., 2017). In this instance, cultural understanding and acceptance of NDEs, which is likely to be lower amongst the general population (Holden et al., 2015), may explain the discrepancy in results. 
Either way, our findings cast doubt on Britton and Bootzin's (2003) claim that NDErs may be physiologically distinct from others and thus predisposed to have NDEs. As Britton and Bootzin did not compare their data with near-death survivors without NDEs, it was not known whether differences were the result of more generalized brain trauma. Similar sleep abnormalities to Britton and Bootzin's were subjectively reported in our study (e.g., shorter sleep duration), yet no significant differences between non-NDErs and NDErs were noted. This result suggests Britton and Bootzin's findings may not be specific only to NDErs and, therefore, are not indicative of a preexisting condition that predisposes individuals to unusual reactions to acute stress such as NDEs. Some anomalies do warrant further investigation, however. Most PTSD findings claim greater REM density (an increased number of rapid eye movements per minute), a greater percent of overall REM sleep, and reduced phase 1 sleep (Pace-Schott et al., 2015). By contrast, Britton and Bootzin (2003) found their NDE group had longer REM sleep latency and fewer REM sleep periods than controls-although the overall amount of REM sleep was similar. So, although both groups of near-death survivors might experience similar sleep disturbances, it is possible that polysomnographic measures may map subtle differences between the two. With respect to the current study, NDErs who had more recent, deeper NDEs reported more sleep abnormalities, suggesting that the NDE itself may also play a role in some way.

\section{Limitations}

An important limitation of this study was that it relied solely on subjective self-assessments of sleep quality. Subjective and objective measures of reported sleep disturbances can often differ, and PSQI scores do not always correlate well with their polysomnographic counterparts (Grandner et al., 2006). Further objective research utilizing both types of near-death survivors-NDErs and non-NDErs-is needed to confirm the presence and type of any sleep abnormalities and whether any differences between the two groups can be detected.

Similarly, we made no attempt to confirm the presence or absence of post traumatic symptoms or assess how the participants felt about their near-death event. Interviewing participants to determine whether or not they find these occurrences sufficiently distressing, as IES scores would indicate, would be highly informative. It would also provide insight into how these effects interrelate with the seemingly positive life changes made. 
Finally, those who volunteer for research may differ from those who do not come forward. Given that our research was promoted as a study examining alterations in sleep patterns after near-death events, persons with sleep issues may have been more motivated to participate. It is not known how representative our sample is of the wider population of NDErs and non-NDErs; thus, results must be interpreted with a degree of caution.

\section{Conclusion}

Sleep changes are commonly reported following NDEs; however, little to no empirical research has assessed this phenomenon. The findings of this study confirm the presence of various subjective sleep abnormalities amongst those who have had NDEs, with prevalence rates significantly higher than normal sleepers in the general New Zealand population. Importantly however, no differences were found between NDErs and non-NDErs, suggesting these sleep alterations occurred in response to the near-death event rather than specifically to an NDE. Data indicate that these sleep abnormalities may be traumarelated; however, it is difficult to determine whether or not the NDErs in our study considered these symptoms distressing or otherwise problematic. Significant positive life changes do not seem to indicate a maladaptive response to the NDE, suggesting alterations in sleep patterns may potentially stem from physiological rather than psychological dysfunction.

\section{References}

Atwater, P. M. H. (2009). Near-death experiences, the rest of the story: What they teach us about living and dying and our true purpose. Hampton Roads.

Baskett, J. J., Wood, P. C., Broad, J. B., Duncan, J. R., English, J., \& Arendt, J. (2001). Melatonin in older people with age-related sleep maintenance problems: a comparison with age matched normal sleepers. Sleep, 24(4), 418-424.

Baskett, J. J., Broad, J. B., Wood, P. C., Duncan, J. R., Pledger, M. J., English, J., \& Arendt, J. (2003). Does melatonin improve sleep in older people? A randomised crossover trial. Age and Ageing, 32(2), 164-170.

Bensimon, M. (2012). Elaboration on the association between trauma, PTSD and posttraumatic growth: The role of trait resilience. Personality and Individual Differences, 52, 782-787.

Blalock, S., Holden, J. M., \& Atwater, P. M. H. (2015). Electromagnetic and other environmental effects following near-death experiences: A primer. Journal of Near-Death Studies, 33, 181-211. https://doi.org/10.17514/JNDS -2015-33-4-p181-211.

Bisson, J. I., Ehlers, A., Matthews, R., Pilling, S., Richards, D., \& Turner, S. 
(2007). Psychological treatments for chronic post-traumatic stress disorder: Systematic review and meta-analysis. British Journal of Psychiatry, 190(2), 97-104.

Britton, W. B., \& Bootzin, R. R. (2004). Near-death experiences and the temporal lobe. Psychological Science, 15(4), 254-258.

Buysse, D. J., Reynolds III, C. F., Monk, T. H., Berman, S. R., \& Kupfer, D. J. (1989). The Pittsburgh Sleep Quality Index: A new instrument for psychiatric practice and research. Psychiatry Research, 28(2), 193-213.

Cohen, J. (1988). Statistical power analyses for the social sciences. Lawrence Erlbaum Associates.

Dekel, S., Ein-Dor, T., \& Solomon, Z. (2012). Posttraumatic growth and posttraumatic distress: A longitudinal study. Psychological Trauma, 4, 94-101.

Edgell, S. E., \& Noon, S. M. (1984). Effect of violation of normality on the $t$ test of the correlation coefficient. Psychological Bulletin, 95(3), 576-583. https://doi .org/10.1037/0033-2909.95.3.576

Fracasso, C., \& Friedman, H. (2012). Electromagnetic aftereffects of near-death experiences: A preliminary report on a series of studies currently under way. Journal of Transpersonal Research, 4(2), 34-55.

Goza, T. H., Holden, J. M., \& Kinsey, L. (2014). Combat near-death experiences: An exploratory study. Military Medicine, 179(10), 1113-1118.

Grandner, M. A., Kripke, D. F., Yoon, I. Y., \& Youngstedt, S. D. (2006). Criterion validity of the Pittsburgh Sleep Quality Index: Investigation in a non-clinical sample. Sleep and Biological Rhythms, 4(2), 129-136.

Greyson, B. (1983). The Near-Death Experience Scale: Construction, reliability, and validity. Journal of Nervous \& Mental Disease, 171, 369-375.

Greyson, B. (2001). Posttraumatic stress symptoms following near-death experiences. American Journal of Orthopsychiatry, 71(3), 368-373.

Greyson, B. (2007). Consistency of near-death experience accounts over two decades: Are reports embellished over time? Resuscitation, 73(3), 407-411.

Greyson, B., Mitchell B., Liester, M., Monument, C., Kinsey, L., Alsum, S., \& Fox, G. (2015). Electromagnetic phenomena reported by near-death experiencers. Journal of Near-Death Studies, 33, 213-243. https://doi.org/10.17514/ JNDS-2015-33-4-p213-243.

Greyson, B., \& Ring, K. (2004). The life changes inventory-revised. Journal of Near-DeathStudies, 23,41-54.https://doi.org/10.17514/JNDS-2004-23-1-p41-54.

Groth-Marnat, G., \& Summers, R. (1998). Altered beliefs, attitudes, and behaviours following near-death experiences. Journal of Human Psychology, 38, $110-125$.

Holden, J. M., Kinsey, L., \& Moore, T. R. (2014). Disclosing near-death experiences to professional healthcare providers and nonprofessionals. Spirituality in Clinical Practice, 1(4), 278-287.

Khanna, S., \& Greyson, B. (2015). Near-death experiences and posttraumatic growth. Journal of Nervous and Mental Disease, 203(10), 749-755.

Klemenc-Ketis, Z. (2013). Life changes in patients after out-of-hospital cardiac arrest. International Journal of Behavioral Medicine, 20(1), 7-12.

Long, J., \& Holden, J. M. (2007). Does the arousal system contribute to near-death and out-of-body experiences? A summary and response. Journal of Near-Death Studies, 25, 135-169. https://doi.org/10.17514/JNDS-2007-25-3-p135-169.

Malow, B. A. (1996). Sleep and epilepsy. Neurologic Clinics, 14(4), 765-789. 
Mollayeva, T., Thurairajah, P., Burton, K., Mollayeva, S., Shapiro, C. M., \& Colantonio, A. (2016). The Pittsburgh Sleep Quality Index as a screening tool for sleep dysfunction in clinical and non-clinical samples: A systematic review and meta-analysis. Sleep Medicine Reviews, 25, 52-73.

Nelson, K., Mattingly, M., Lee, S. A., \& Schmitt, F. A. (2006). Does the arousal system contribute to near death experience? Neurology, 66, 1003-1009.

Nelson, L., Mattingly, M., \& Schmitt, F. A. (2007). Out-of-body experiences and arousal. Neurology, 68, 794-795.

Nouri, F. M., \& Holden, J. M. (2008). Electromagnetic aftereffects of neardeath experiences. Journal of Near-Death Studies, 27, 83-110. https://doi .org/10.17514/JNDS-2008-27-2-p83-110.

Noyes, R., Fenwick, P., Holden, J. M., \& Christian, S. R. (2009). Aftereffects of pleasurable western adult near-death experiences. In J. M. Holden, B. Greyson, \& D. James (Eds.), The handbook of near-death experiences: Thirty years of investigation (pp. 41-62). Praeger/ABC-CLIO.

Pace-Schott, E. F., Germain, A., \& Milad, M. R. (2015). Sleep and REM sleep disturbance in the pathophysiology of PTSD: The role of extinction memory. Biology of Mood \& Anxiety Disorders, 5(1), 3. https://doi.org/10.1186/s13587-015 -0018-9

Ring, K., \& Rosing, C. J. (1990). The Omega Project: An empirical study of the NDE-prone personality. Journal of Near-Death Studies, 8, 211-239. https:// doi.org/10.17514/JNDS-1990-8-4-p211-239.

Shalev, A., Liberzon, I., \& Marmar, C. (2017). Post-traumatic stress disorder. New England Journal of Medicine, 376(25), 2459-2469.

Spoormaker, V. I., \& Montgomery, P. (2008). Disturbed sleep in post-traumatic stress disorder: secondary symptom or core feature? Sleep Medicine Reviews, 12(3), 169-184.

Schwaninger, J., Einsenberg, P. R., Schechtman, K. B., \& Weiss, A. N. (2002). A prospective analysis of near-death experiences in cardiac arrest patients. Journal of Near-Death Studies, 20, 215-232. https://doi.org/10.17514/JNDS -2002-20-4-p215-232.

Sundin, E. C., \& Horowitz, M. J. (2002). Impact of Event Scale: Psychometric properties. British Journal of Psychiatry, 180(3), 205-209.

Tassell-Matamua, N., Lindsay, N., Bennett, S., Valentine, H., \& Pahina, J. (2017). Does learning about near-death experiences promote psycho-spiritual benefits in those who have not had a near-death experience? Journal of Spirituality in Mental Health, 19(2), 95-115.

van Lommel, P., van Wees, R., Meyers, V., \& Elfferich, I. (2001). Near-death experience in survivors of cardiac arrest: A prospective study in the Netherlands. Lancet, 358, 2039-2045.

Walch, O. J., Cochran, A., \& Forger, D. B. (2016). A global quantification of "normal" sleep schedules using smartphone data. Science Advances, 2(5), e1501705.

Weiss D. S., \& Marmar, C. R. (1997). The Impact of Event Scale-Revised. In J. P. Wilson \& T. M. Keane (Eds.), Assessing psychological trauma and PTSD (pp. 399-411). Guilford Press.

Weiss, D. S. (2007). The Impact of Event Scale: Revised. In J. P. Wilson \& C. C. So-Kum Tang (Eds.), Cross-cultural assessment of psychological trauma and PTSD (pp. 219-238). Springer. 
Wu, Z., Xu, J., \& Sui, Y. (2016). Posttraumatic stress disorder and posttraumatic growth coexistence and the risk factors in Wenchuan earthquake survivors. Psychiatry Research, 237, 49-54.

Wu, K., Zhang, Y., Liu, Z., Zhou, P., \& Wei, C. (2015). Coexistence and different determinants of posttraumatic stress disorder and posttraumatic growth among Chinese survivors after earthquake: Role of resilience and rumination. Frontiers in Psychology, 6, 1043. https:// doi.org/10.3389/fpsyg.2015.01043

Zingrone, N. L., \& Alvarado, C. S. (2009). Pleasurable Western adult near-death experiences: Features, circumstances, and incidence. In J. M. Holden, B. Greyson, \& D. James (Eds.), The handbook of near-death experiences: Thirty years of investigation (pp. 17-40). Praeger/ABC-CLIO. 